Bangladesh Journal of Neuroscience 2017; Vol. 33 (2): 83-88

\title{
Association of Serum Uric Acid level in Patients with Alzheimer's Disease
}

\author{
AHTESAM MS ${ }^{1}$, HABIB MA ${ }^{2}$, ISLAM MR ${ }^{3}, \mathrm{KHAN} \mathrm{MRK}^{4}$, RAHMAN HZ ${ }^{5}$, RIZVI AN ${ }^{6}$, \\ BHUIYAN MM ${ }^{7}$, BARMAN KK ${ }^{8}$, SHOWKAT $S^{9}$, ISLAM MM ${ }^{10}$, RAKNUZZAMAN $M^{11}$, \\ ISLAM MF ${ }^{12}$, SARKER I ${ }^{13}$, HANNAN MA ${ }^{14}$
}

\begin{abstract}
:
Background: Alzheimer's disease is the most common cause of dementia. Uric acid is the end product of purine metabolism in humans and acts as a natural antioxidant, accounting up to $60 \%$ of the free radical scavenging activity in human blood to prevent free radicals induced oxidative cell injury. This study aimed to explore the association between serum uric acid level and cognitive impairment of Alzheimer's disease patients compared to those of the non-demented age and sex matched controls. Methods: This case control study was carried out in the department of neurology, BSMMU, Dhaka. Total 116 patients were enrolled as study population after satisfying inclusion and exclusion criteria. Among them, 58 were grouped as case and rest 58 were control. All blood samples for serum uric acid were measured in the Biochemistry lab, Department of Biochemistry, BSMMU, Dhaka. Results: A signiûcant reduction of serum uric acid levels in the $A D$ group was found compared to those of the control group $(4.35 \pm 1.59 \mathrm{Vs}$ $6.89 \pm 1.68)$ which was statistically significant $(p<0.001)$. We also found a positive correlation between serum uric acid levels with severity of Alzheimer's disease $(r p=$ $0.633, P<0.001)$. Among demographic variables educational qualification was statistically significant $(p=0.006)$ in $A D$ patients. Conclusion: This study showed that oxidative injuries have an important role in the pathogenesis of $A D$. Higher levels of uric acid are associated with a decreased risk of dementia and better cognitive function later in life.
\end{abstract}

Key words: Antioxidants, Alzheimer's disease, Uric acid, Oxidative Injuries etc.

\section{Introduction:}

According to WHO (2015), the number of people living with dementia worldwide in 2015 was estimated at 47.47 million, will reach 75.63 million in 2030 and 135.46 million in 2050 ${ }^{1}$. In Bangladesh $4,60,000$ people was estimated with dementia in
2015 , will reach $8,34,000$ in 2030 and $21,93,000$ people will live with dementia in 2050 respectively². Elderly people over 65 years of age Alzheimer's disease $(A D)$ is the most common form of dementia (70\%). Pathological hallmarks of Alzheimer's disease in the brains are neuritic plaques

1. Dr. Mohammad Saifullah Ahtesam,Phase-B resident (MD- Neurology), Dept. of Neurology, BSMMU, Dhaka, Bangladesh.

2. Dr. Md. Ahsan Habib,Associate professor, Dept. of Neurology, BSMMU, Dhaka, Bangladesh.

3. Prof. (Dr.) Md.Rafiqul Islam, Professor \& Chairman, Dept. of Neurology, BSMMU, Dhaka, Bangladesh.

4. Prof. (Dr.) Md. Rezaul Karim Khan, Professor, Dept. of Neurology, BSMMU, Dhaka, Bangladesh.

5. Prof. (Dr.) Hasan Zahidur Rahman, Professor, Dept. of Neurology, BSMMU, Dhaka, Bangladesh.

6. Prof. (Dr.) Abu Nasir Rizvi, Professor, Dept. of Neurology, BSMMU, Dhaka, Bangladesh.

7. Prof. (Dr.) Md. Moniruzzaman Bhuiyan, Professor, Dept. of Neurology, BSMMU, Dhaka, Bangladesh.

8. Dr. Kanuj Kumar Barman, Associate professor, Dept. of Neurology, BSMMU, Dhaka, Bangladesh.

9. Dr. Syeeda Showkat, Associate professor, Dept. of Radiology and imaging, BSMMU, Dhaka, Bangladesh.

10. Dr. Md. Monirul Islam, Phase-B resident (MD- Neurology), Dept. of Neurology, BSMMU, Dhaka, Bangladesh.

11. Dr. Md. RaknuzzamanPhase-B resident (MD- Neurology), Dept. of Neurology, BSMMU, Dhaka, Bangladesh.

12. Dr. Md. Fakrul Islam, EMO, Dept. of Neurology, Dhaka Medical College Hospital, Dhaka, Bangladesh.

13. Dr. Imran Sarker, Registrar (Clinical Neurology), NINS\&H, Dhaka, Bangladesh.

14. Prof. (Dr.) M A Hannan, Professor, Dept. of Neurology, BSMMU, Dhaka, Bangladesh. 
composed mainly by extracellular fibrillary $\beta$-amyloid deposition, with subsequent intra neuronal hyper phosphorylated tau protein aggregation $^{3}$. Increasing evidence suggests that oxidative stress has a key role in late-onset sporadic forms, which are the majority of Alzheimer's disease cases. Abnormal levels of oxidative stress have been reported in Alzheimer's disease in both the brain and blood stream ${ }^{4}$. Changes in Alzheimer's disease that produce a pro oxidative imbalance have been attributed to decrease in antioxidant defenses, toxicity related to amyloid- $\beta$, and/or altered metal metabolism in the brain and peripheral tissues ${ }^{4}$.

The free radical hypothesis of aging suggests that the age-related accumulation of reactive oxygen species (ROS) may result in damage to major cell components in specific brain region ${ }^{5-8}$. Central nervous system (CNS) is vulnerable to free radical damage owing to the high brain oxygen consumption, low content of antioxidants enzymes, compared to other tissues ${ }^{7}$.

Uric acid is the final product of purine metabolism in humans ${ }^{8}$. Uric acid is a natural antioxidant, accounting for up to $60 \%$ of the free radical scavenging activity in human blood (Ames et al., 1981). Uric acid can scavenge superoxide, the hydroxyl radical, and singlet oxygen ${ }^{9}$. Uric acid is also very effective in preventing peroxynitrite from nitrating the tyrosine residues of proteins, thereby preventing the inactivation of cellular enzymes and modification of the cytoskeleton ${ }^{10}$. Uric acid also has the ability to bind with iron and inhibit irondependent ascorbate oxidation, preventing an increased production of free radicals that can further contribute to oxidative damage ${ }^{11}$. Thus, a reduced Uric acid concentration may decrease the ability of the body to prevent peroxynitrite and other free radicals induced oxidative cell injury ${ }^{12}$. The protective effect of Uric acid on neuro degeneration has been widely studied, which has revealed elevated serum levels of Uric acid to be associated with slower disease progression in patients with Alzheimer's disease and other neurodegenerative diseases ${ }^{13}$. Some recent study showed Uric acid levels are significantly $(p=0.033)$ lower in Alzheimer's disease patients in comparison to control subjects. Uric acid may have a protective role against Alzheimer's disease ${ }^{12}$.

A significant reduction in the albumin, bilirubin, and uric acid levels in the Alzheimer's disease group was found compared to those of the control group ${ }^{14}$. Higher levels of uric acid are associated with a decreased risk of dementia and better cognitive function later in life ${ }^{15}$. But another report found no difference ${ }^{16}$. So the exact role of uric acid in Alzheimer's disease and even whether the low serum uric acid level is a cause or a consequence of disease is not clear. More studies are required to clarify the meaning and possible therapeutic implications of uric acid changes in Alzheimer's disease. With this aim we tried to evaluate the relationship between serum uric acid level and cognitive impairment of Alzheimer's patients and compared them with a group of nondementic age and sex matched control considering other possible markers of age-related cognitive decline.

\section{Methods:}

In this case control study was carried out in the department of neurology, Bangabandhu Sheikh Mujib Medical University. After ethical clearance from institutional review board (IRB-BSMMU), total 58 AD patients were grouped as case and same number of non-demented age and sex matched patients were grouped as control. All AD patients were diagnosed by NINCDS-ADRDA (2007) criteria $^{17}$. The bangla version of Mini mental state examination was used to evaluate the cognitive functions of all patients ${ }^{18}$. It tests five areas of cognitive functions: orientation, registration, attention/calculation, recall and language. Folstein (1975) interpretation of MMSE scores was used for severity assessment where score 21-25 means mild dementia, score 10-20 means moderate dementia and score $<10$ indicates severe dementia ${ }^{19}$. Non-demented was defined as a score of $>25$ orbetter. Both groups of patients had no major medical illnesses such as hypercholesterolemia, hypertension, renal disease, diabetes. Informed written consent was obtained from all subjects or legal guardians. From each patient, $3 \mathrm{cc}$ of whole blood sample was taken by standard venipuncture from antecubital vein after 
proper asepsis. All blood samples for serum uric acid were measured in the Department of Biochemistry, BSMMU as soon as possible by using photometric technology in Beckman Coulter AU680 auto analyzer ${ }^{20}$. The medical records, demographics, clinical and laboratory records of all patients were examined. All data were checked. Data processing and statistical analysis was done by SPSS (statistical package for social science) version 22 programme.

\section{Results:}

No significant difference were observed between case and control groups for age $(p=0.062)$, gender $(p=0.0851)$, occupation $(p=0.689)$ and smoking $(p=0.440)$, respectively (Table 1$)$. Educational qualification showed significant difference between two study groups $(p=0.006)$ (Table 1$)$. $12.1 \% A D$ patients had positive family history (Figure 1). Mean $( \pm S D)$ age of dementia duration in case group was $3.0( \pm 1.4)$ years. Most of the $A D$ patients were presented with moderate dementia $(69 \%)$ followed my mild dementia (22.4\%) then severe dementia (8.9\%).

A significant reduction of serum uric acid levels in the AD group was found compared to those of the control group $(4.35 \pm 1.59 \mathrm{Vs} 6.89 \pm 1.68)$ which was statistically significant $(p<0.001)$ (Table 2$)$. The scorers of MMSE showed a positive correlation with serum uric acid levels $(r p=0.633, P<0.001)$ but duration of dementia didn't find no positive correlation with serum uric acid level (Figure 2).

Table-I

Demographic characteristic of study groups with case versus control

\begin{tabular}{lccc}
\hline \multirow{2}{*}{ Variables } & \multicolumn{2}{c}{ Groups } & P-values \\
\cline { 2 - 3 } & Case $(\mathrm{n}=58)$ & Control $(\mathrm{n}=58)$ & \\
\hline Age (years) & $65 \pm 9.32$ & $61 \pm 11.09$ & 0.062 \\
Gender (\%) & $34(58.6)$ & $33(56.9)$ & 0.851 \\
$\quad$ Male & $24(41.4)$ & $25(43.1)$ & \\
$\quad$ Female & $23(39.7)$ & $18(31.0)$ & 0.689 \\
Occupational status (\%) $\quad 12(20.7)$ & $11(19)$ & \\
$\quad$ Housewife & $23(39.7)$ & $29(44.7)$ & \\
$\quad$ Service holder & & & \\
$\quad$ Others & $9(15.5)$ & $7(12.1)$ & \\
Educational qualifications (\%) & $30(51.7)$ & $31(53.5)$ & \\
$\quad$ Illiterate & $19(32.8)$ & $20(34.4)$ & \\
$\quad$ Less then 10 class & & & \\
$\quad$ More then 10 class & $23(39.7)$ & $19(32.8)$ & \\
Smoking (\%) & $35(60.3)$ & $39(67.2)$ & \\
$\quad$ Smoker & & & \\
$\quad$ Non smoker & &
\end{tabular}

Table-II

Serum uric acid values of study groups with case versus control

\begin{tabular}{lcccc}
\hline & \multicolumn{2}{c}{ Groups } & Total (Case \& Control) & P value \\
\cline { 2 - 4 } Uric acid $(\mathrm{mg} / \mathrm{dl})$ & Case $(\mathrm{n}=58)$ & Control $(\mathrm{n}=58)$ & $\mathrm{n}=116$ & \\
\hline Mean $\pm(\mathrm{SD})$ & $4.35 \pm 1.59$ & $6.89 \pm 1.68$ & $5.62 \pm 2.07$ & $<0.001$ \\
\hline
\end{tabular}




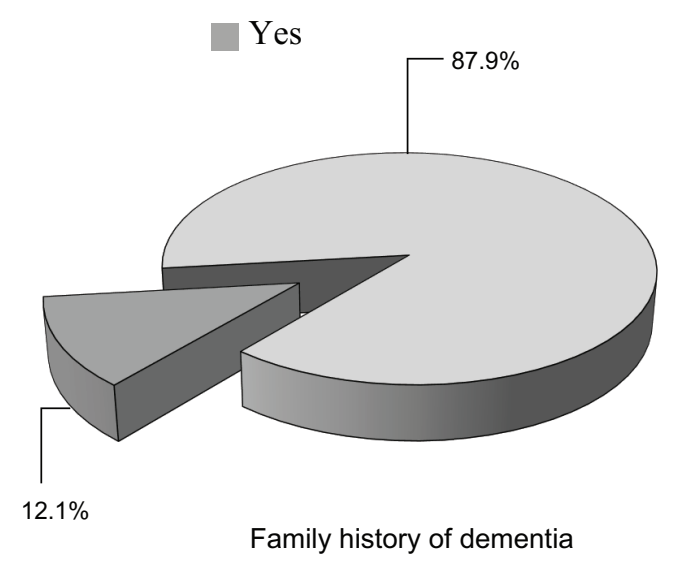

Fig.-1: Pie chart of Alzheimer's disease patients (case group) according to family history of dementia $(n=58)$

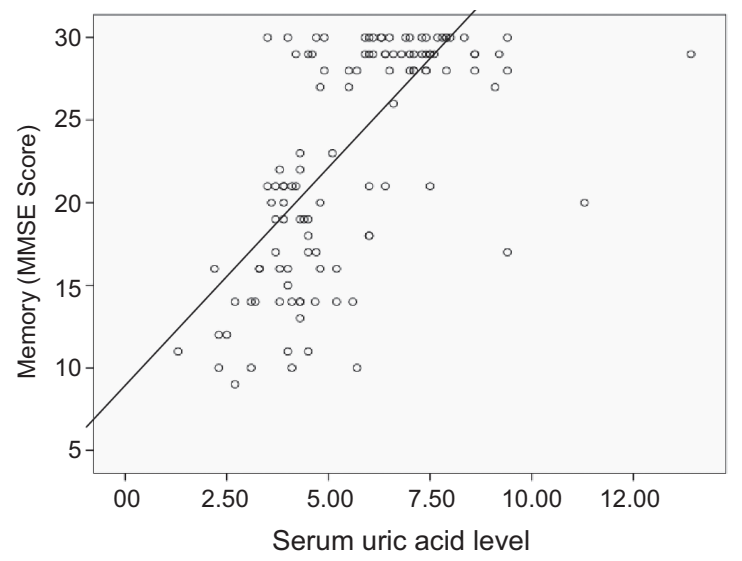

Fig.-2: Scatter diagram showing positive correlation of Serum uric acid level and MMSE scores in in both case and control groups $(n=116)$

Table-III

Unadjusted Odds Ratios of being Alzheimer's disease

\begin{tabular}{lcccccc}
\hline Parameter & DF & Standard error & P-value & Odds ratio & \multicolumn{2}{c}{$\mathrm{Cl}(95 \%)$} \\
\cline { 5 - 6 } & & & & & Min & Max \\
\hline Serum uric acid & 1 & 0.1834 & $<.0001$ & $\mathbf{0 . 3 5 6}$ & 0.249 & 0.511 \\
Age & 1 & 0.0187 & 0.0642 & 1.035 & 0.998 & 1.074 \\
Sex & 1 & 0.3760 & 0.8509 & 0.932 & 0.446 & 1.947 \\
Education & 1 & & & & & \\
No education & & 0.6951 & 0.2939 & 0.482 & 0.123 & 1.883 \\
Primary & & 0.6700 & 0.5892 & 0.696 & 0.187 & 2.589 \\
Secondary & & 0.5742 & $\mathbf{0 . 0 2 0 9}$ & 0.266 & 0.086 & 0.818 \\
Higher secondary & & 0.7962 & $\mathbf{0 . 0 0 1 5}$ & 0.080 & 0.017 & 0.383 \\
Occupation & 1 & & & & & \\
House wife & & 0.4777 & 0.7054 & 1.198 & 0.470 & 3.055 \\
Others & & 0.4710 & 0.4717 & 0.713 & 0.283 & 1.793 \\
Smoking & 1 & 0.3877 & 0.4402 & 1.349 & 0.631 & 2.884 \\
\hline
\end{tabular}

Table-IV

Adjusted Odds Ratios of being Alzheimer's disease

\begin{tabular}{lcccccc}
\hline Parameter & DF & Standard error & P-value & Odds ratio & \multicolumn{2}{c}{$\mathrm{Cl}(95 \%)$} \\
\cline { 5 - 7 } & & & & & Min & Max \\
\hline Serum uric acid & 1 & 0.2221 & $<\mathbf{0 . 0 0 1}$ & $\mathbf{0 . 3 2 1}$ & 0.208 & 0.497 \\
Education & 1 & & & & & \\
No education & & 1.0655 & 0.9815 & 1.025 & 0.127 & 8.273 \\
Primary & & 1.1043 & 0.4334 & 2.375 & 0.273 & 20.689 \\
Secondary & & 0.8672 & 0.2729 & 0.386 & 0.071 & 2.114 \\
High secondary & & 1.0489 & 0.2262 & 0.281 & 0.036 & 2.196 \\
\hline
\end{tabular}




\section{Discussion:}

This current study where mean $( \pm S D)$ value of serum uric acid level was reduced in $A D$ patients as compared to those of control group (4.35 \pm 1.59 Vs $6.89 \pm 1.68)$. Which was statistically significant $(p<0.001)$. It was consistent with the other studies like Ames et al., $(1981)^{9}$, Khateebet al. $(2014)^{12}$, Kim et al. (2006) ${ }^{15}$, Cervellati et al.,(2012) ${ }^{21}$. All this studies including this one supports the hypothesis that oxidative injuries could play an important role in the pathogenesis of Alzheimer's disease. Reduced serum uric acid level may decrease the ability of the body to prevent free radicals induced cellular injury. Low serum uric acid was not a constant finding in every AD patients. There are possible two hypotheses regarding this finding of uric acid. It is possible that persons with already low serum uric acid levels, who were unable to combat against free radical toxicity leading to the development of inûammation followed by generalized cell destruction, resulting cortical atrophy. Ultimately there will be development of Alzheimer's disease and other neurodegenerative disorders. However, it is also possible that, low serum uric acid level was a consequence of excess consumption or utilization of uric acid for body defense against free radical induced inflammation. So, low serum uric acid levels were a cause or a consequence of Alzheimer's disease is debatable.

This study was also found that MMSE score showed a positive correlation with serum uric acid levels in this study which was analyzed by spearman rank correlation coefficient test. Positive correlation coefficient was observed $(r p=0.633)$ which was statistically significant $(p<0.001)$. This finding also coincides with previous studies ${ }^{12,15,22}$. Therefore it may be stated that severity of Alzheimer's disease was affected by serum uric acid level. Although this study was found a negative correlation between serum uric acid level with duration of dementia ( $r p=-0.142$ with $p=0.287$ ).

We used a logistic regression analysis to get the effect of serum uric acid on Alzheimer's disease. The adjusted odds ratio was 0.327 . That means the odds of developing Alzheimer disease is 0.327 for a participant if a one unit increase of uric acid after eliminating the confounding effect of education. That is, participants have $67.3 \%$ lower odds of being developing subsequent Alzheimer disease for a one-unit increase of uric acid.

High serum uric acid levels are associated with a number of disease like Gout, hypertension, cardiovascular disease and kidney disease. So, the use of uric acid in the treatment of neurodegenerative diseases including Alzheimer's disease is controversial. Although Settle et al. $(2014)^{23}$ was suggested that combining uric acid precursors such as inosine with ascorbic acid may have therapeutic benefits for AD patients, but dose and duration of treatment have not been yet determined.

\section{Limitation:}

The present case control study was a single centered study, involving only one clinical and laboratory evaluation of the serum uric acid of the individuals without any further follow-up. The changes in serum uric acid levels over time could not be taken into consideration, and therefore, it is not possible to discriminate whether there were differences in serum uric acid levels that preceded the onset of the dementia or whether they developed during the course of the diseases.

\section{Recommendations:}

Elderly people should take adequate amount of protein $(0.8 \mathrm{gm} / \mathrm{kg} /$ day $)$. Further multi-centered prospective cohort study with larger sample size could be carried out to see the association of serum uric acid level with the clinical course of Alzheimer's disease. Another Large population based multicenter double blinded studies are needed to find out any treatment response of serum uric acid level against Alzheimer's disease.Comprehensive steps should be taken by government to address this health hazard.

\section{Conclusion:}

The present study revealed that serum uric acid level was significantly lower in AD patients in comparison to control group. So, this biomarker might be considered as a risk factor for Alzheimer's disease. In addition this study suggests that there was significant relationship between serum uric acid level and severity of disease although there was no correlation between serum uric acid level and duration of AD. 


\section{References:}

1. World Health Organization. The Epidemiology And Impact Of Dementia Current State Future Trends. 2015; Retrieved from http:// www.who.int/ mental _ health/neurology/ dementia/en/WHO /MSD/MER/15(3), 1-4.

2. Alzheimer's Association, Overview of Alzheimer's Disease- Alzheimer's Disease Facts and Figures. Alzheimer's \& Dementia. 2016 ; 12(4): 3-71.

3. Weiner MW, Veitch DP and Aisen PS. The Alzheimer's disease neuroimaging initiative: a review of papers published since its inception.Alzheimer's and Dementia. 2012; 8(1):S1-S68.

4. Smith MA, Rottkamp CA,Nunomura A, Raina $A K$ and Perry G. Oxidativestress in Alzheimer'sdisease. Biochimicaet Biophysica Acta. 2000; 1502(1): 139-144.

5. Reiter RJ. Oxidative process and antioxidant defense mechanisms in the aging brain.FASEB Journal. 1995; 9: 526-33.

6. Poon HF, Calabrese V, Scapagnini G and Butterfield DA. Free radicals: key to brain ageing and hemeoxygenase as a cellular response to oxidative stress. $J$ Gerontol A Bio Sci. 2004; 59: 478-93.

7. CoyelJT andPuttfarcken P. Oxidative stress, glutamate and neurodegenerative disorders. Science. 1993; 262: 689 - 95.

8. Glantzounis GK, Trimoyiannis EC, Kappas AM and Galaris DA. Uric acid and oxidative stress.Current Pharmaceutical Design. 2005; 11(32): 4145-51.

9. Ames NB, Cathcart R, Schwiers E and Hochstein P. Uric acid provides an antioxidant defense in humans against oxidant- and radical-caused aging and cancer: $A$ hypothesis.Proc. Natl. Acad. Sci. USA. 1981; 78: 6858-62.

10. Pacher P, Beckman JS, Liaudet L. Nitric oxide and peroxynitrite in health and disease. Physiol Rev. 2007; 87: 315-424.

11. Davies KJ, Sevanian A, Muakkassah-Kelly SF, Hochstein P. Uric acid iron ion complexes:A new aspect of the antioxidant functions of uric acid. Biochem J. 1986; 235: 747-754.

12. Khateeb AE, Althaher A, Al-khateeb M and Musawi AH. Relation between Uric Acid and Alzheimer's disease in Elderly Jordanians.Journal of Alzheimer's disease. 2014; 44: 859-65.

13. Abraham A and Dory VE. Influence of serum uric acid levels on prognosis and survival in amyotrophic lateral sclerosis: a metaanalysis.J Neurol. 2014; 261(6): 1133-8.

14. Euser MS, Hofman A, Westendorp JGR and Breteler BMM. Serum uric acid and cognitive function and dementia. Brain.2009; 132: 377 82.

15. Kim TS, Pae CU, Yoon SJ and Lee UC. Decreased plasma antioxidants in patients with Alzheimer's disease.Int J Geriatr Psychiatry. 2006; 21: 344-48.

16. Polidori MC, Stahl W, Eichler O, Niestroj I and Sies $\mathrm{H}$. Profiles of antioxidents in human plasma. Free Radical Biology and Medicine. 2001; 30(5): 456-62.

17. Dubois B, Feldman H, Jacova C, Dekoski S, Barber-Gateau P and Cummings J. (2007). Research criteria for the diagnosis of Alzheimer's disease: revising the NINCDSADRDA criteria. Lancet Neurol.2007; 6: 73446.

18. Mohammad QD, Habib M, Bhowmik NB, Alam M, Chowdhury N and Alam B. Technical Committee for the Development of MMSE in Bangladesh. 2010.

21. Cervellati $C$, Cremonini E, Bosi $C$ and Magon S. Systemic Oxidative Stress in Older Patients with Mild Cognitive Impairment or Late Onset Alzheimer's disease. Current Alzheimer Research. 2013; 10(4): 1-8.22.Zhu X, Raina KA, Perry G and Smith AM. Alzheimer's disease: the two hit hypothesis. Lancet Neurol. 2004; 3:219-26.

23. Settle Tand Klandorf H.The Role of Uric Acid as an Antioxidant in Selected Neurodegenerative Disease Pathogenesis: A Short Review.Brain Disorders and Therapy.2014; 3(3): 1-5. 